AARP INTERNATIONAL THE JOURNAL

VOLUME $11-2018$ EDITION

AATR

Real Possibilities

New York:

First Age-Friendly State in the Nation

By Andrew Cuomo 


\title{
New York: First Age-Friendly State in the Nation
}

\author{
By Andrew Cuomo
}

$\mathrm{H}_{\mathrm{s}}$ ere in New York State, we are proud of our legacy of leadership on civil rights and social issues - from women's suffrage in the 19th and 20th centuries to marriage equality in the 21st. In August 2017 we added a new accomplishment to our rich history by becoming the first state in the nation enrolled in the World Health Organization's (WHO's) Global Network of Age-Friendly Cities and AARP's Network of Age-Friendly States.

Age-friendly communities, as defined by WHO and AARP, commit to improving their communities by addressing the eight domains of livability. Municipalities throughout the country are network members, including 16 in New York, but New York State is the first and only state accepted into the WHO and AARP age-friendly networks.

Age-friendly is not about old age it is about the value of all ages. It is about designing communities for everyone that strengthen people's connections to each other, improve health, increase physical activity and support, and advance the economic environment through proactive design and future-based planning. That is exactly what we have done in New York through our age-friendly agenda — we are helping older adults stay in their neighborhoods by building and preserving more than 8,600 affordable housing units for them since 2011; we are encouraging social participation by using technologies to help older adults navigate their health and health care needs; we are improving the built environment and making our streets safer for people of all ages. From housing to transportation, we have streamlined and improved existing programs to make sure they reach older New Yorkers in a more effective way.

As in the rest of the nation, New York's population is growing older. For far too long the aging population has been portrayed as one that contributes less and takes more. But here, we know that the social, economic, and intellectual capital that older adults contribute to their communities and to our state is unmistakable. With their years of life, work, and family experience, almost 700,000 older New Yorkers contribute more than 119 million hours of community service at an economic value of more than $\$ 3$ billion annually. Older New Yorkers and baby boomers make up 63 percent - or
\$379 billion - of all the household income generated in New York State. They support local businesses and schools through home ownership, contributing significantly to the local and state economy. And our older adults want to stay in New York, their home. According to AARP, 90 percent of New York residents surveyed say they want to retire in New York. And we want them to stay as well.

Since 2011, my administration has been fighting to make New York more equitable for people of all ages. Over the past seven years, New York has become a national leader in creating clean, livable, and sustainable communities by pioneering multifaceted programs that support aging in place, coupled with an unparalleled suite of smart-growth reforms that directly support AARP's eight domains of livable, age-friendly communities:

- Since signing the Complete Streets Act in 2011, 12 counties and over 100 New York villages, towns, and cities have now adopted Complete Streets policies to consider the safe, convenient access and mobility of all roadway users of all ages and abilities. 


\section{"For far too long the aging population has been portrayed as one that contributes}

less and takes more. But here, we know that the social, economic, and intellectual capital that older adults contribute to their communities and to our state is unmistakable."

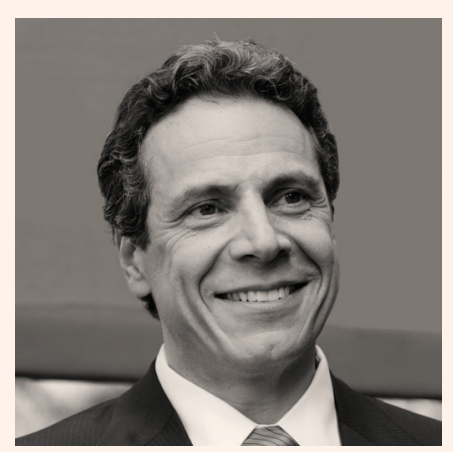

Andrew Cuomo GOVERNOR OF NEW YORK UNITED STATES
- Through the Livable NY initiative, we have been working collaboratively to provide municipalities with technical assistance as they seek to make planning decisions related to livability.

- We have created 8,659 affordable housing units for seniors, 1,270 of which are part of my House NY 2020 plan, which will ultimately create and preserve over 100,000 units of affordable housing throughout the state by 2021 .

- We announced a comprehensive plan to better protect senior citizens from financial exploitation and foreclosure by expanding enhanced multidisciplinary teams statewide to combat elder abuse; by establishing the Elder Abuse Certification Program, which amends the banking law to empower banks to place holds on potentially fraudulent transactions; and by strengthening legislation that will protect senior homeowners with reverse mortgages.
- As part of the 2017 Downtown Revitalization Initiative, the state is awarding $\$ 100$ million to 10 downtown areas, prioritizing awards to municipalities that have age-friendly policies in place that improve livability, including the presence of mixeduse spaces, modern zoning codes, streets that are both walkable and bikeable, nondiscrimination laws, and other policies that make communities more livable for all ages.

- Earlier this year we created the nation's first statewide mobile app to connect more than 3.7 million older adults with easily accessible material about benefits, programs, and services, including information regarding health and wellness, housing, and transportation options.

Key to our successes has been a strong partnership with local leaders and local communities across New York. A critical component to improving a community's health is embedding elements of wellness within economic development strategies to create or renovate built 


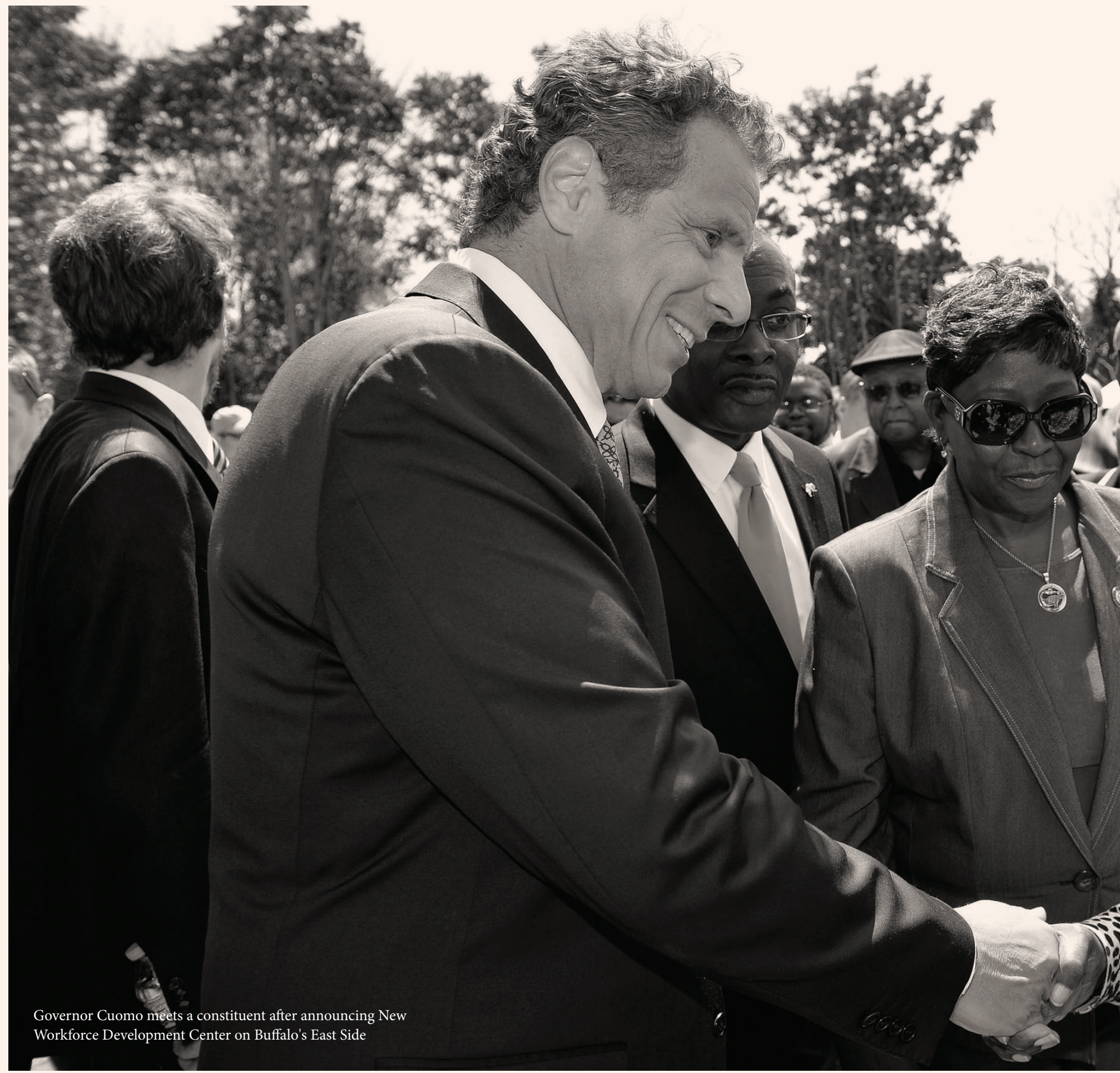

environments that will improve population health by increasing physical activity, promoting cleaner air, creating safer streets, and making communities desirable places to live and work. This multifaceted approach makes people healthier, which, in turn, makes communities healthier, which saves money and boosts the economy. These are the underlying strategies called for in my Prevention Agenda, the state health im- provement plan, which has helped New York become the 13th healthiest state in the nation, up from the 20th in 2011.

Being designated the first age-friendly state is not the end of our efforts, but the beginning. We will build on our achievements by continuing to work with local governments, residents, and businesses to embed the eight domains of age-friendly policy into all aspects of community development to make positive changes in communities that are attractive to all, regardless of age.

New York State is diverse in many ways - geographically, culturally, ethnically, and in age. Our residents come from all over the world and from all walks of life, helping to make New York the great state that it is. Out of many, we are one. New York's people are our greatest assets, and it is incumbent on us to be 


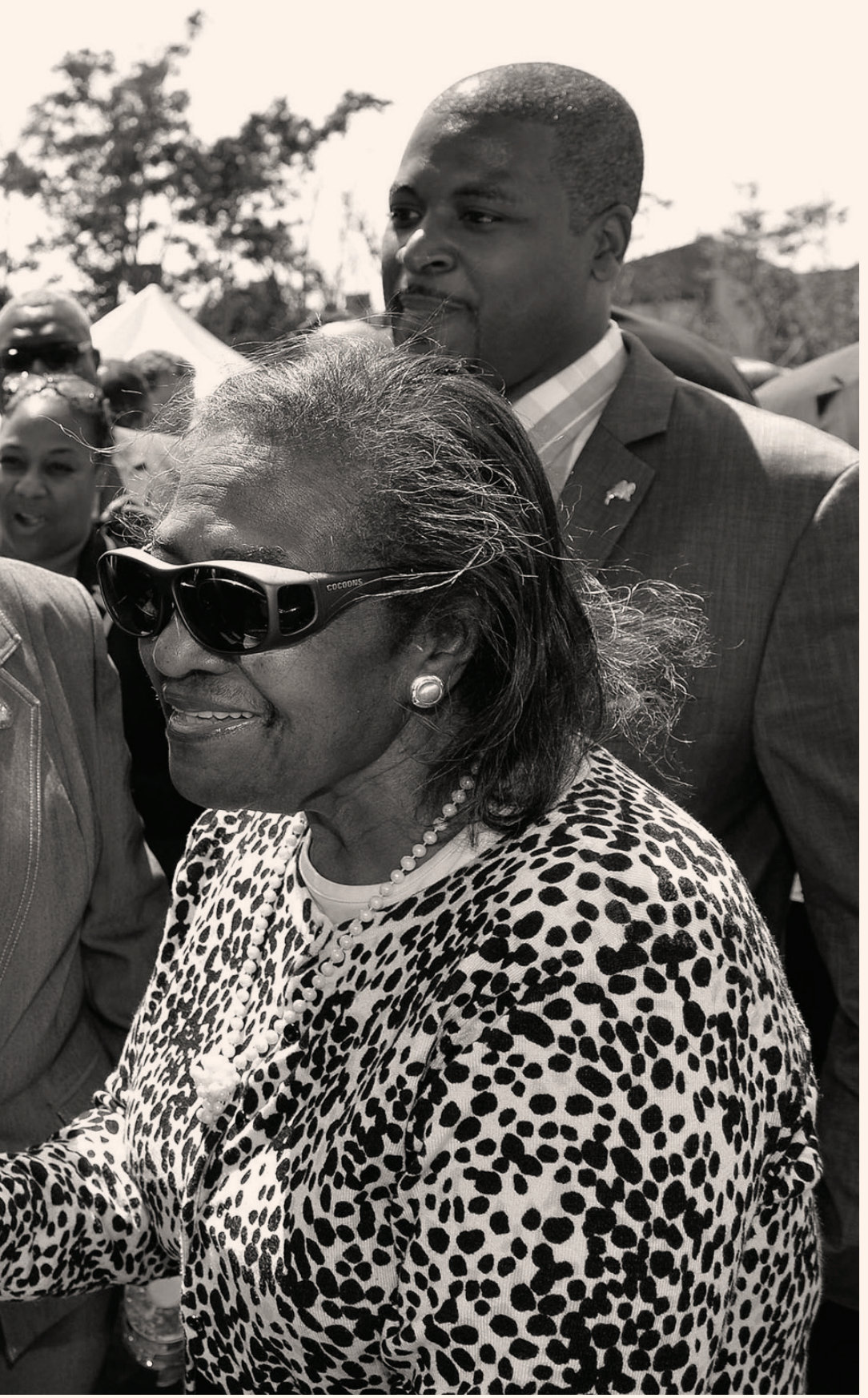

at the forefront in promoting positive

change to make sure New York remains

a place where our older adults can con-

tinue to live and thrive.
With their years of life, work, and family experience, almost 700,000 older New Yorkers contribute more than 119 million hours of community service at an economic value of more than \$3 billion annually. Older New Yorkers and baby boomers make up 63 percent - or $\$ 379$ billion - of all the household income generated in New York State.

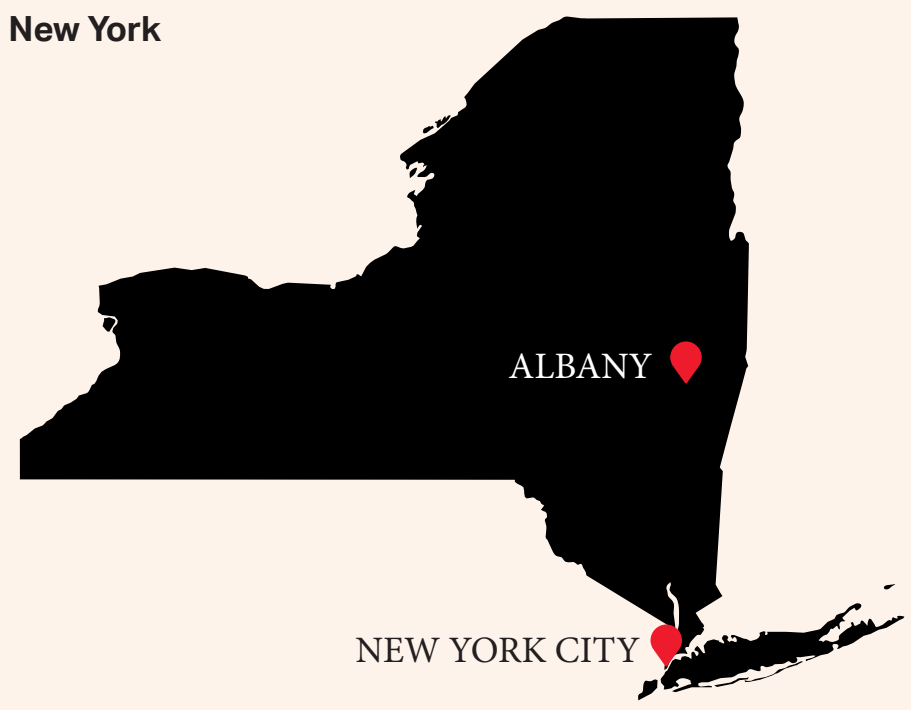

NICKNAME

The Empire State

TOTAL AREA

$141,300 \mathrm{sq} \mathrm{km}(54,555 \mathrm{sq} \mathrm{mi})$

POPULATION

$19,745,289$ (ranked $4^{\mathrm{TH}}$ in the US)

CAPITAL

Albany

LARGEST CITY

New York City

$8,537,673$ (est. population, 2016)

DEMONYM

New Yorker

PEOPLE AGE $50+$

$6,301,539(2010)$

PEOPLE AGE $85+$

390,874 (2010) 
AARP International engages global stakeholders to spark solutions that strengthen communities, protect the vulnerable and enable people around the world to pursue their goals and dreams. Working with governments, civil society and the private sector, we are focused on enhancing the quality of life for people as they age. We serve as the global voice for AARP, a social change organization with a membership of more than 37 million.

THE JOURNAL ONLINE

aarpinternational.org/journal

AARP INTERNATIONAL ONLINE

aarpinternational.org

FACEBOOK

facebook.com/aarpintl

TWITTER

@aarpintl

CONTACT

AARP International

601 E Street, NW

Washington, DC 20049

United States

T +1 2024342398

E international@aarp.org

AARP International: The Journal is a publication of AARP. The views expressed herein do not necessarily represent policies of AARP and should not be construed as endorsements. The mention of a product or service herein is solely for information to our readers and may not be used for any commercial purpose. AARP, which was established in 1958, is a nonprofit, nonpartisan organization with tens of millions of members ages 50 and older. State offices are located in all 50 states, the District of Columbia, Puerto Rico, and the Virgin Islands.

January 2018

()2018, AARP

Reprinting with permission only. 